\title{
The Relationship Between Obstructive Sleep Apnea Hypopnea Syndrome and Inflammatory Markers and Quality of Life in Subjects With Acute Coronary Syndrome
}

\author{
Hao Wu MD, Xiandao Yuan MD PhD, Li Wang MD, Jingwu Sun MD PhD, \\ Jinghua Liu MD PhD, and Yongxiang Wei MD PhD
}

\begin{abstract}
BACKGROUND: The objective of this work was to examine the relationship between obstructive sleep apnea (OSA) and inflammatory markers and quality of life in patients with acute coronary syndrome, especially undergoing percutaneous coronary intervention. METHODS: One hundred eighteen subjects were admitted with acute coronary syndrome over 1 y who had symptoms of OSA and positive polysomnography on admission. Of these subjects, 53 underwent primary percutaneous coronary intervention during their admission, and 65 had medical management. We then compared inflammatory markers by OSA status. We also assessed cardiac symptoms using the Seattle Angina Questionnaire and sleep symptoms using the Epworth Sleepiness Scale. RESULTS: Subjects in the percutaneous coronary intervention group had a higher oxygen desaturation index $(\mathrm{ODI})(P=.02)$ and apnea-hypopnea index $(\mathrm{AHI})(P=.048)$ compared with those in the medical management group. In percutaneous coronary intervention subjects, the moderate-severe OSA group (AHI $\geq 15 / \mathrm{h})$ had a higher hematocrit $(P=.047)$, homocysteine $(P=.01)$, and highsensitivity $C$-reactive protein $(P=.045)$ compared with those with no or mild OSA $(A H I<15 / h)$. There was a significant correlation between high-sensitivity C-reactive protein and both AHI $(\mathrm{r}=0.46, P=.001)$ and ODI $(\mathrm{r}=0.47, P<.001)$. Those with moderate-severe OSA had higher Epworth Sleepiness Scale $(P=.002)$, greater physical limitation $(P=.01)$, and lower treatment satisfaction and disease perception $(P=.007)$, as judged by subscales of the Seattle Angina Questionnaire, compared with those with no or mild OSA. Finally, subjects undergoing percutaneous coronary intervention with lower AHI $(\mathrm{r}=0.48, P<.001)$ and $\mathrm{ODI}(\mathrm{r}=0.49, P<.001)$ reported higher treatment satisfaction. CONCLUSIONS: Subjects with acute coronary syndrome undergoing percutaneous coronary intervention who had moderate-severe OSA showed higher levels of inflammatory mediators and lower treatment satisfaction and disease perception. These factors may increase the risk of adverse sequelae by increasing the systemic inflammatory response. Key words: obstructive sleep apnea syndrome; OSA; heart disease; inflammation; quality of life. [Respir Care 2016;61(9):1207-1216. (C) 2016 Daedalus Enterprises]
\end{abstract}

Introduction

There is growing evidence that obstructive sleep apnea (OSA) is associated with the pathogenesis and prognosis of coronary heart disease. ${ }^{1}$ For example, existing retro-

The authors are affiliated with Beijing An Zhen Hospital, Capital Medical University, Beijing, China.

This work was supported by National Natural Science Foundation of China Grant 81470567 . The authors have disclosed no conflicts of interest. spective studies show that comorbid OSA confers increased risk of adverse outcomes after percutaneous coronary in-

\footnotetext{
Supplementary material related to this paper is available at http:// www.rcjournal.com.

Correspondence: Yongxiang Wei MD PhD, Beijing Anzhen Hospital, Capital Medical University, 2th Anzhen Road, Chaoyang District, Beijing 100029, China. E-mail: weiyongxiang1208@163.com.
}

DOI: $10.4187 /$ respcare.04571 


\section{Effect of OSA on Percutaneous Coronary Intervention Subjects}

tervention. ${ }^{2,3}$ Conversely, CPAP treatment reduces the occurrence of acute coronary syndrome in subjects with $\mathrm{OSA}^{4}$ and decreases the risk of major adverse cardiac events (cardiac death, reinfarction, and target vessel revascularization) in those undergoing percutaneous coronary intervention. ${ }^{3,5}$ In patients with cardiovascular disease, the prevalence of OSA ranges between 47 and $83 \% .^{6}$ Because percutaneous coronary intervention has been considered a sign of poor long-term prognosis of acute coronary syndrome, ${ }^{7}$ optimizing related diseases in these patients is critical.

The pathophysiologic mechanisms linking OSA and coronary heart disease remain unclear. Most experts suggest that multifactorial processes, including alteration of the coagulation pathways, metabolic dysregulation, and systemic and vascular inflammation (Fig. 1), underlie the effects of OSA on coronary artery disease. Indeed, inflammatory processes are critical in the pathogenesis of atherosclerosis. Previous findings emphasize that the inflammatory cascade might play an important role in the cardiovascular effects of OSA. ${ }^{8}$ The inflammatory cascade involves different pathways by the activation of a large number of humoral mediators, and there is plenty of evidence supporting its pivotal role in all phases of atherosclerosis. ${ }^{8}$

To date, little is known about the prevalence of OSA among subjects with acute coronary syndrome, especially those undergoing percutaneous coronary intervention. In addition, the potential effect of OSA on clinical outcomes and its mechanism of action in those with acute coronary syndrome and OSA who undergo percutaneous coronary intervention remain to be determined. Thus, to test the hypothesis that comorbid OSA might be associated with increased inflammatory mediators in this setting, we determined the association of severity of OSA with relevant biomarkers in subjects presenting with acute coronary syndrome.

\section{Methods}

\section{Study Population}

We selected consecutive patients who were hospitalized in the Cardiovascular Department of Beijing Anzhen Hospital, a major cardiovascular center, from November 2013 to November 2014. We included 204 adult subjects with acute coronary syndrome who were suspected of having OSA on screening at admission (snoring with repeated apnea, daytime sleepiness, morning headaches with or without associated increased blood pressure, memory loss, and other symptoms). Those with such symptoms underwent polysomnography (PSG) in our Sleep Medicine Laboratory (see below). We excluded patients with New York Heart Association functional class III/IV heart failure

\section{QUICK LOOK}

\section{Current knowledge}

Comorbid OSA confers increased risk of adverse outcomes after percutaneous coronary intervention. The potential effect of OSA on clinical outcomes and its mechanism of action in those with acute coronary syndrome and OSA who undergo percutaneous coronary intervention remains to be determined.

\section{What this paper contributes to our knowledge}

Adults with acute coronary syndrome undergoing percutaneous coronary intervention had a high prevalence of moderate to severe OSA. Percutaneous coronary intervention subjects had a higher oxygen desaturation index score, a higher level of inflammatory mediators, and a lower treatment satisfaction and disease perception, which may increase the risk of adverse events.

( $n=19)$, cardiomyopathy $(n=13)$, and unclear history narrative or inadequate records $(n=2)$. We did not screen or enroll patients with clinical instability requiring immediate intervention.

We included subjects diagnosed with coronary artery disease by angiography (more than one vessel having $\geq 50 \%$ luminal stenosis) and limited entry to those undergoing primary percutaneous coronary intervention and those between ages 35 and $75 \mathrm{y}$. Patients with cardiogenic shock, acute infection or chronic inflammation, respiratory insufficiency, central apnea hypoventilation ( $\geq 50 \%)$, or previous treatment with CPAP or oral appliances were excluded. After screening, a total of 53 subjects with primary percutaneous coronary intervention were included in our analysis (Fig. 2) and also 65 receiving medical management without percutaneous coronary intervention. All subjects gave written, informed consent for the procedures and research protocol, which was approved by the ethics committee of our institution.

\section{Classification of OSA}

Sleep evaluations were performed by a trained specialist in sleep medicine at Beijing Anzhen Hospital Sleep Center during admission. We recorded each subject's diagnostic PSG parameters, which included measures of the electromyogram, electro-oculogram, electroencephalogram, electrocardiogram, pulse oximetry, naso-oral air flow, and thoracoabdominal excursions. Sleep, arousals, and periodic leg movements were scored by American Academy of Sleep Medicine standards. ${ }^{9}$ Respiratory events were scored manually as follows: Apneas were identified when the 


\section{Effect of OSA on Percutaneous Coronary Intervention Subjects}

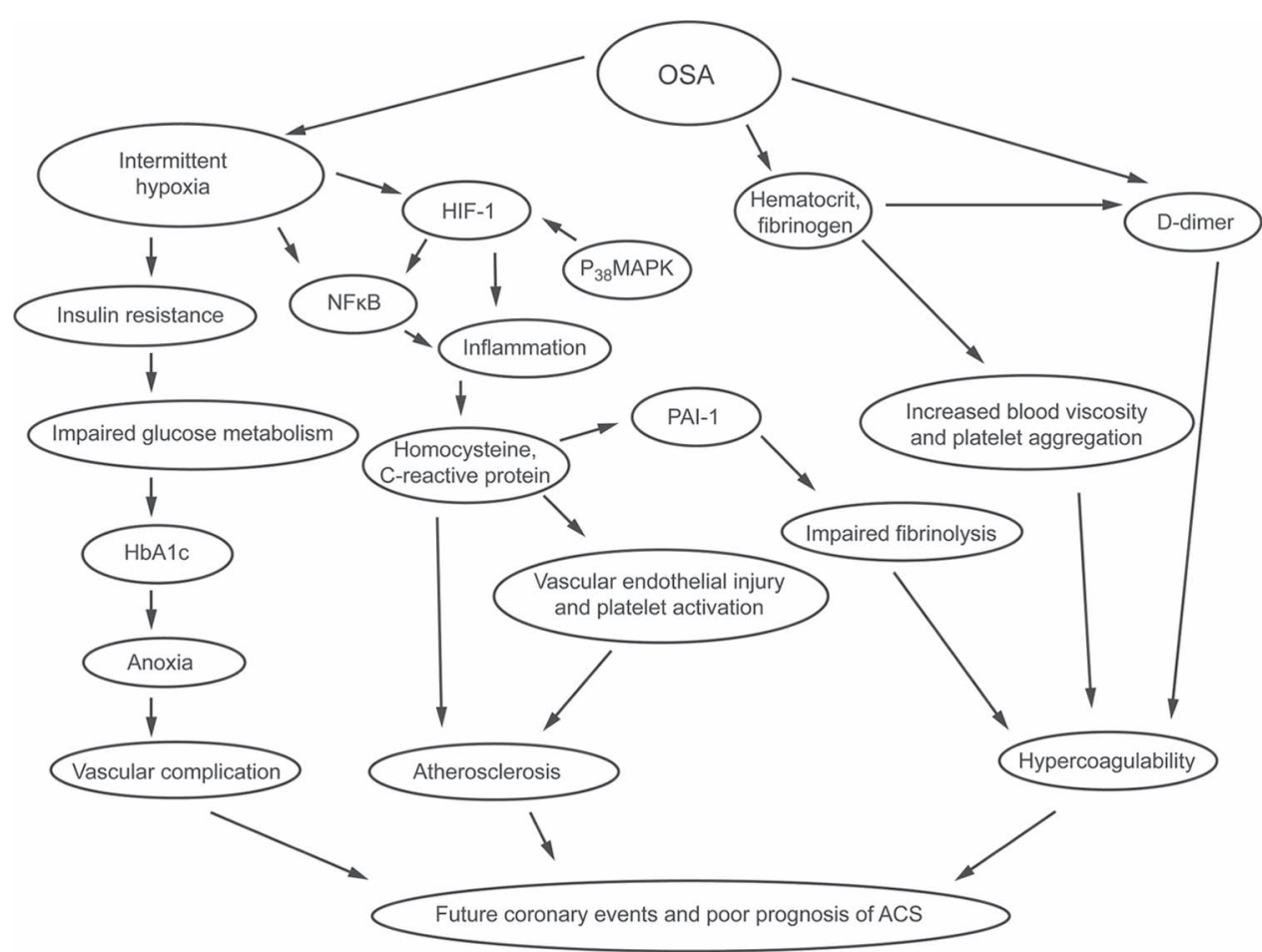

Fig. 1. Multifactorial processes involving a wide range of mechanisms of obstructive sleep apnea causing increased risk of future coronary events and poor prognosis of acute coronary syndrome. OSA = obstructive sleep apnea, ACS = acute coronary syndrome, HbA1c $=$ glycated haemoglobin, HIF-1 = hypoxia-inducible factor $-1, \mathrm{NF}-\kappa \mathrm{B}=$ nuclear factor kappa $\mathrm{B}, \mathrm{MAPK}=$ mitogen-activated protein kinase, $\mathrm{PAl}-1=$ plasminogen activator inhibitor-1.

air-flow amplitude on the nasal cannula was $<10 \%$ of baseline and no flow occurred on the oral thermistor. Hypopneas were identified when air-flow amplitude was reduced by $30 \%$ from baseline, and the event was followed by $4 \% \mathrm{O}_{2}$ desaturation. ${ }^{9}$ Apnea-hypopnea index (AHI) was defined as the sum of apneas and hypopneas divided by total sleep time, as suggested by the criteria of the American Academy of Sleep Medicine. ${ }^{9}$ OSA is the most common type of sleep apnea and is caused by complete or partial obstructions of the upper airway. It is characterized by repetitive episodes of shallow or paused breathing during sleep, despite effort to breathe, and is associated with a reduction in blood oxygen saturation and other physiologic derangements. Severity was classified as follows: normal (AHI $<5 / \mathrm{h})$, mild OSA $(5 / \mathrm{h} \leq \mathrm{AHI}<15 / \mathrm{h})$, moderate OSA $(15 / \mathrm{h} \leq \mathrm{AHI}<30 / \mathrm{h})$, and severe OSA (AHI $\geq 30 / \mathrm{h}$ ). We collected data on coexisting conditions, morning blood pressure, and body mass index of each person at the time of PSG. The personnel collecting these data were different from the ones collecting data from the PSG and confirming the sleep diagnoses and also different from those who collected the laboratory data before percutaneous coronary intervention. For the analyses below, we grouped OSA subjects into ether moderate and severe OSA subjects (moderate-severe) or normal and mild OSA subjects (normal-mild).

\section{Laboratory Data}

We measured coagulation and fibrinolytic indexes (fibrinogen, fibrin degradation product, and D-dimer), hematocrit, and inflammatory markers (high-sensitivity Creactive protein, homocysteine, and B-type natriuretic peptide). All of the tests were performed on the day of PSG, using standard methodologies in our certified hospital laboratory.

\section{Quality of Life Assessment}

The Seattle Angina Questionnaire is a 19-item instrument used to quantify the severity of cardiac symptoms and related functional limitations and impairment of quality of life among those with established disease. It consists of 5 domains (physical limitation, anginal stability, anginal frequency, treatment satisfaction, and disease perception $)^{10}$ and is scored by assigning each response a value of 1 (low function) to 10 (high function) and summing across items within each of the 5 dimensional scales. Scale scores are then transformed to a scale of $0-100$ by subtracting the lowest possible scale score, dividing the remainder by the range of the scale, and multiplying that by $100 .{ }^{10}$ Higher scores correlate with better function/satisfaction and fewer limitations. Each subscale monitors a unique dimension of 


\section{Effect of OSA on Percutaneous Coronary Intervention Subjects}

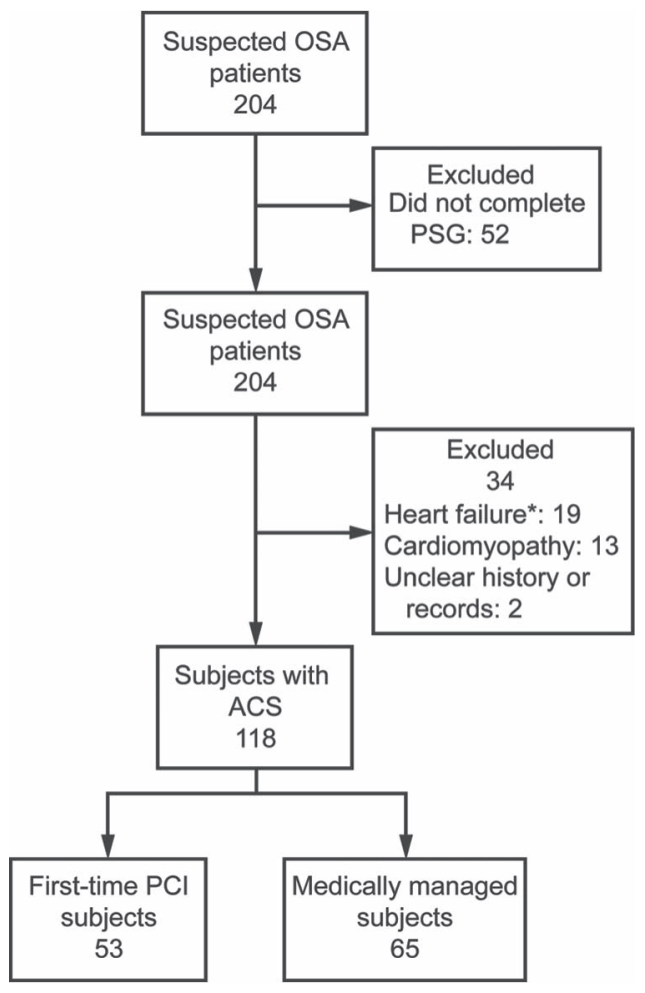

Fig. 2. Flow chart. OSA = obstructive sleep apnea, $P S G=$ polysomnography, $\mathrm{ACS}=$ acute coronary syndrome, $\mathrm{PCl}=$ percutaneous coronary intervention. * New York Heart Association functional class III/IV heart failure.

coronary artery disease. The Chinese version is a validated, responsive, and reliable method of assessment. ${ }^{11}$

\section{Epworth Sleepiness Scale}

The Epworth Sleepiness Scale ${ }^{12}$ is a simple, self-administered questionnaire that is a subjective measurement of the subject's general level of daytime sleepiness and propensity to fall asleep in common situations. Higher scores indicate more sleepiness.

\section{Survey Administration}

We administered the Seattle Angina Questionnaire and the Epworth Sleepiness Scale to subjects on the day of admission to the hospital.

\section{Statistical Analysis}

Characteristics of the study population and laboratory tests results are presented as mean $\pm \mathrm{SD}, n(\%)$, and mean (with 95\% CI). Independent $t$ tests or chi-square tests were used to compare demographics of the medical management and percutaneous coronary intervention groups. These groups were compared by OSA status using 2-independent sample $t$ test and chi-square or Fisher exact test. Multivariate logistic regression analysis was used to assess the independent risk factors associated with undergoing percutaneous coronary intervention. We also determined predictors of high-sensitivity C-reactive protein levels and treatment satisfaction score using linear regression analysis. A $P$ value of $<.05$ was considered to be statistically significant. Tests were 2-tailed. All analyses were performed using SPSS 19.0 for Windows (SPSS, Chicago, Illinois).

\section{Results}

\section{Subject Characteristics}

We included 118 subjects who met entry criteria. These were divided into 2 groups: the percutaneous coronary intervention group $(n=53)$ and the medical management group $(n=65)$. Characteristics of the study population are described in Table 1 . There was a statistically significant difference between the 2 groups in the prevalence of myocardial infarction (percutaneous coronary intervention vs medical management: $20.8 \%$ vs $3.1 \%, P=.003$ ). However, the 2 groups were similar in terms of age, sex ratio, body mass index, blood pressure, ejection fraction, related diseases (arrhythmia, diabetes, and stroke), and history of smoking, alcohol, and drug use (aspirin, $\beta$ blocker, angiotensin-converting enzyme inhibitors, and statins).

Sleep status by PSG results is also described in Table 1. The oxygen desaturation index (ODI) (medical management vs percutaneous coronary intervention, $18.6 \pm 16.1$ vs $26.3 \pm 20.9, P=.03$ ) and AHI (medical management vs percutaneous coronary intervention, $18.6 \pm 16.1$ vs $25.6 \pm 21.0, P=.048$ ) were worse in those undergoing percutaneous coronary intervention. However, the groups were similar in terms of lowest oxygen saturation (medical management vs percutaneous coronary intervention, $85.7 \pm 5.9 \%$ vs $83.9 \pm 7.8 \%, P=.16)$ and percentage of saturation $<90 \%$ (medical management vs percutaneous coronary intervention, $4.4 \pm 13.3 \%$ vs $6.1 \pm 12.4 \%$, $P=.47)$. After adjusting for sex and age, ODI, lowest $\mathrm{S}_{\mathrm{pO}_{2}}$, and $\mathrm{S}_{\mathrm{pO}_{2}}$ were not associated with treatment with percutaneous coronary intervention (Table 2). The percentage of moderate to severe OSA subjects in the percutaneous coronary intervention group tended to be higher than that in the medical management group (64.2\% vs $52.3 \%, P=.20$ ) (Fig. 3), although this was not statistically significant.

Percutaneous coronary intervention subjects $(n=53)$ were divided into 2 groups: the normal to mild OSA group $(n=19)$ and the moderate to severe OSA group $(n=34)$ (Table 3). There was no statistical difference 
Table 1. Study Population

\begin{tabular}{|c|c|c|c|}
\hline & $\mathrm{MM}(n=65)$ & PCI $(n=53)$ & $P$ \\
\hline Age, mean \pm SD y & $54.8 \pm 11.1$ & $54.7 \pm 7.8$ & .96 \\
\hline Male sex, $\%$ & 63.1 & 75.5 & .17 \\
\hline $\mathrm{BMI}$, mean $\pm \mathrm{SD} \mathrm{kg} / \mathrm{m}^{2}$ & $27.9 \pm 4.0$ & $28.3 \pm 4.2$ & .62 \\
\hline $\mathrm{SBP}$, mean $\pm \mathrm{SD} \mathrm{mm} \mathrm{Hg}$ & $127.3 \pm 15.0$ & $129.4 \pm 16.4$ & .48 \\
\hline $\mathrm{DBP}$, mean $\pm \mathrm{SD} \mathrm{mm} \mathrm{Hg}$ & $76.7 \pm 10.8$ & $76.0 \pm 9.2$ & .63 \\
\hline $\mathrm{EF}, \%$ & $65.4 \pm 6.1$ & $65.7 \pm 5.5$ & .80 \\
\hline UAP, $\%$ & 73.8 & 88.7 & .061 \\
\hline MI, \% & 3.1 & 20.8 & .003 \\
\hline Arrhythmia, \% & 9.2 & 5.7 & .51 \\
\hline $\mathrm{DM}, \%$ & 24.6 & 17.0 & .27 \\
\hline Stroke, \% & 4.6 & 3.8 & $>.99$ \\
\hline Smoking, $\%$ & 47.7 & 37.7 & .71 \\
\hline Alcohol, \% & 21.5 & 9.4 & .08 \\
\hline Aspirin, \% & 26.2 & 24.5 & .84 \\
\hline$\beta$ blocker, $\%$ & 49.2 & 62.3 & .16 \\
\hline ACEI, \% & 9.2 & 3.8 & .29 \\
\hline Statins, $\%$ & 7.7 & 3.8 & .46 \\
\hline $\mathrm{AHI}$, mean $\pm \mathrm{SD}$ & $18.6 \pm 16.1$ & $25.6 \pm 21.0$ & .048 \\
\hline $\mathrm{ODI}$, mean $\pm \mathrm{SD}$ & $18.6 \pm 16.1$ & $26.3 \pm 20.9$ & .03 \\
\hline Lowest $\mathrm{S}_{\mathrm{pO}_{2}}$, mean $\pm \mathrm{SD} \%$ & $85.7 \pm 5.9$ & $83.9 \pm 7.8$ & .16 \\
\hline $\mathrm{S}_{\mathrm{pO}_{2}}<90 \%$, mean $\pm \mathrm{SD} \%$ & $4.4 \pm 13.3$ & $6.1 \pm 12.4$ & .47 \\
\hline \multicolumn{4}{|l|}{$\overline{\mathrm{MM}=\text { medical management }}$} \\
\hline \multicolumn{4}{|l|}{$\mathrm{PCI}=$ percutaneous coronary intervention } \\
\hline \multicolumn{4}{|l|}{$\mathrm{BMI}=$ body mass index } \\
\hline \multicolumn{4}{|l|}{$\mathrm{SBP}=$ systolic blood pressure } \\
\hline \multicolumn{4}{|l|}{$\mathrm{DBP}=$ diastolic blood pressure } \\
\hline \multicolumn{4}{|l|}{$\mathrm{EF}=$ ejection fraction } \\
\hline \multicolumn{4}{|l|}{$\mathrm{UAP}=$ unstable angina pectoris } \\
\hline \multicolumn{4}{|l|}{$\mathrm{MI}=$ myocardial infarction } \\
\hline \multicolumn{4}{|c|}{ DM $=$ diabetes mellitus } \\
\hline \multirow{2}{*}{\multicolumn{4}{|c|}{$\begin{array}{l}\text { ACEI }=\text { angiotensin-converting enzyme inhibitors } \\
\text { AHI }=\text { apnea-hypopnea index }\end{array}$}} \\
\hline \multicolumn{3}{|l|}{$\mathrm{AHI}=$ apnea-hypopnea index } & \\
\hline \multicolumn{4}{|c|}{$\begin{array}{l}\mathrm{ODI}=\text { oxygen desaturation index, which indicates the number of oxygen desaturations }(\geq 4 \% \\
\text { reduction of } \mathrm{S}_{\mathrm{pO}_{2}} \text { compared with the baseline) in } 1 \mathrm{~h} \text { of recording and by the time span in } \\
\text { which oxygen saturation stays }<90 \%\end{array}$} \\
\hline
\end{tabular}

Table 2. Independent Factors Associated With Percutaneous Coronary Intervention by Multivariate Logistic Regression Analysis

\begin{tabular}{lccr}
\hline \hline \multicolumn{1}{c}{ Factors } & OR & $95 \% \mathrm{CI}$ & \multicolumn{1}{c}{$P$} \\
\hline ODI & 1.024 & $0.996-1.053$ & .10 \\
Lowest $\mathrm{S}_{\mathrm{pO}_{2}}$ & 1.000 & $0.913-1.095$ & $>.99$ \\
$\mathrm{~S}_{\mathrm{pO}_{2}}<90 \%$ & 0.995 & $0.953-1.038$ & .81
\end{tabular}

Results were adjusted for age and sex. Model $\mathrm{R}^{2}=0.075$. Area under the receiver operating characteristic curve was 0.623 .

$\mathrm{OR}=$ odds ratio

ODI $=$ oxygen desaturation index

in the 2 groups for age, sex ratio, body mass index, blood pressure, ejection fraction, percentage of myocardial infarction and Killip function class I, related diseases (arrhythmia, diabetes, and stroke), and current smoking, alcohol, and drug use (aspirin, $\beta$ blocker, angiotensin-converting enzyme inhibitors, and statins).

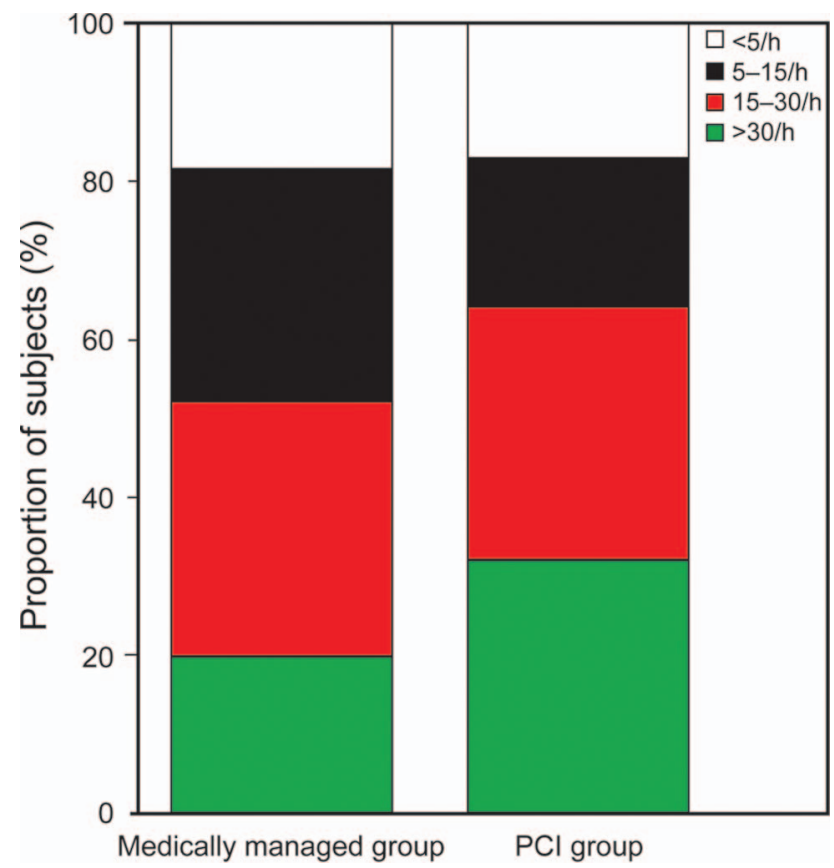

Fig. 3. Severity of obstructive sleep apnea-hypopnea syndrome according to number of events/hour using apnea hypopnea index scores. $\mathrm{PCl}=$ percutaneous coronary intervention.

\section{Inflammatory Markers in Percutaneous Coronary Intervention Subjects}

For percutaneous coronary intervention subjects (shown in Table 3), there were no statistically significant differences in fibrinogen $(P=.15)$, fibrin degradation product $(P=.25), \mathrm{D}$-dimer $(P=.30)$, and B-type natriuretic peptide $(P=.22)$ (adjusted for the type of acute coronary syndrome and Killip function class) between those with more versus less severe OSA. However, percutaneous coronary intervention subjects with moderate-severe OSA showed worse hematocrit $(P=.047)$, homocysteine $(P=.01)$, and high-sensitivity $C$-reactive protein $(P=.045)$ (adjusted for the type of acute coronary syndrome and Killip function class) compared with normal-mild OSA subjects. Regression analysis (Table 4) showed that high-sensitivity C-reactive protein levels were correlated with AHI ( $\mathrm{r}=0.46, P=.047)$ and ODI (r = 0.47, $P=.03$ ) (Fig. 4a).

\section{Quality of Life in Percutaneous Coronary Intervention Subjects}

There were no statistically significant differences in Seattle Angina Questionnaire subscales for anginal stability $(P=.15)$ and anginal frequency $(P=.65)$ between the different OSA severity groups. However, percutaneous coronary intervention subjects with moderate-severe OSA showed worse Epworth Sleepiness Scale $(P=.002)$, phys- 


\section{Effect of OSA on Percutaneous Coronary Intervention Subjects}

Table 3. Characteristics of the Percutaneous Coronary Intervention Group by Obstructive Sleep Apnea Severity

\begin{tabular}{|c|c|c|c|}
\hline \multirow{2}{*}{ Characteristics } & \multicolumn{2}{|c|}{ OSA Status } & \multirow{2}{*}{$P$} \\
\hline & Normal-Mild (AHI $<15 / \mathrm{h}, n=19$ ) & Moderate-Severe $(\mathrm{AHI} \geq 15 / \mathrm{h}, n=34)$ & \\
\hline Age, mean \pm SD y & $52.6 \pm 8.7$ & $55.9 \pm 7.3$ & .14 \\
\hline Male sex, $\%$ & 63.2 & 85.3 & .07 \\
\hline $\mathrm{BMI}$, mean $\pm \mathrm{SD} \mathrm{kg} / \mathrm{m} 2$ & $26.6 \pm 2.8$ & $28.5 \pm 3.5$ & .052 \\
\hline $\mathrm{SBP}$, mean $\pm \mathrm{SD} \mathrm{mm} \mathrm{Hg}$ & $124.5 \pm 13.4$ & $132.1 \pm 17.4$ & .11 \\
\hline $\mathrm{DBP}$, mean $\pm \mathrm{SD} \mathrm{mm} \mathrm{Hg}$ & $76.1 \pm 10.7$ & $76.0 \pm 8.4$ & $>.99$ \\
\hline $\mathrm{EF}$, mean $\pm \mathrm{SD} \%$ & $67.3 \pm 4.0$ & $64.9 \pm 6.1$ & .15 \\
\hline Arrhythmia, \% & 0 & 8.8 & .18 \\
\hline Killip Fc I, \% & 84.2 & 91.2 & .75 \\
\hline MI, \% & 5.3 & 29.4 & .08 \\
\hline $\mathrm{DM}, \%$ & 26.3 & 11.8 & .17 \\
\hline Stroke, \% & 5.3 & 2.9 & .67 \\
\hline Smoking, \% & 31.6 & 41.2 & .49 \\
\hline Alcohol, \% & 15.8 & 5.9 & .34 \\
\hline Aspirin, $\%$ & 31.6 & 20.6 & .37 \\
\hline$\beta$ blocker, $\%$ & 57.9 & 64.7 & .62 \\
\hline ACEI, \% & 0 & 5.9 & .53 \\
\hline Statins, $\%$ & 5.3 & 2.9 & .67 \\
\hline FBG, median $(95 \% \mathrm{CI}) \mathrm{g} / \mathrm{L}$ & $2.9(2.5-3.2)$ & $3.2(2.9-3.5)$ & .15 \\
\hline FDP, median $(95 \% \mathrm{CI}) \mu \mathrm{g} / \mathrm{ml}$ & $1.6(1.2-2.0)$ & $1.8(1.6-2.1)$ & .25 \\
\hline D-dimer, median (95\% CI) $\mu \mathrm{g} / \mathrm{ml}$ & $77.0(52.4-101.6)$ & $96.4(72.0-120.9)$ & .30 \\
\hline HCT, median $(95 \% \mathrm{CI}) \%$ & $40.7(38.2-43.1)$ & $43.3(42.3-44.3)$ & .047 \\
\hline $\mathrm{HCY}$, median $(95 \% \mathrm{CI}) \mu \mathrm{mol} / \mathrm{L}$ & $12.0(10.0-14.0)$ & $20.0(15.4-24.4)$ & .01 \\
\hline hsCRP, median $(95 \% \mathrm{CI}) \mathrm{mg} / \mathrm{L}$ & $2.4(0.8-4.0)$ & $7.3(4.2-10.4)$ & $.045^{*}$ \\
\hline BNP, median $(95 \% \mathrm{CI}) \mathrm{pg} / \mathrm{ml}$ & $37.8(25.3-50.4)$ & $95.2(38.3-152.0)$ & $.22 *$ \\
\hline $\mathrm{PL}$, mean $\pm \mathrm{SD}$ & $57.2 \pm 16.0$ & $45.5 \pm 15.8$ & .01 \\
\hline $\mathrm{AS}$, mean $\pm \mathrm{SD}$ & $38.2 \pm 15.3$ & $30.9 \pm 18.5$ & .15 \\
\hline $\mathrm{AF}$, mean $\pm \mathrm{SD}$ & $59.5 \pm 22.5$ & $62.1 \pm 18.6$ & .65 \\
\hline $\mathrm{TS}$, mean $\pm \mathrm{SD}$ & $70.9 \pm 10.8$ & $61.1 \pm 11.8$ & .004 \\
\hline $\mathrm{DP}$, mean $\pm \mathrm{SD}$ & $65.8 \pm 14.1$ & $53.4 \pm 16.0$ & .007 \\
\hline \multirow{2}{*}{\multicolumn{4}{|c|}{$\begin{array}{l}\text { * Adjusted for myocardial infarction and Killip function class. } \\
\text { OSA = obstructive sleep apnea }\end{array}$}} \\
\hline \multirow{2}{*}{\multicolumn{4}{|c|}{$\begin{array}{l}\text { OSA }=\text { obstructive sleep apnea } \\
\text { BMI }=\text { body mass index }\end{array}$}} \\
\hline & & & \\
\hline \multicolumn{4}{|l|}{$\mathrm{SBP}=$ systolic blood pressure } \\
\hline \multicolumn{4}{|l|}{ DBP $=$ diastolic blood pressure } \\
\hline \multirow{2}{*}{\multicolumn{4}{|c|}{$\mathrm{EJ}=$ ejection fraction }} \\
\hline & & & Killip Fc I = Killip classification I \\
\hline \multirow{2}{*}{\multicolumn{4}{|c|}{$\begin{array}{l}\mathrm{MI}=\text { myocardial infarction } \\
\mathrm{DM}=\text { diabetes mellitus }\end{array}$}} \\
\hline & \multicolumn{3}{|c|}{$\mathrm{DM}=$ diabetes mellitus } \\
\hline \multirow{2}{*}{\multicolumn{4}{|c|}{$\begin{array}{l}\text { ACEI }=\text { angiotensin-converting enzyme inhibitors } \\
\text { FBG }=\text { fibrinogen }\end{array}$}} \\
\hline & & & \\
\hline \multicolumn{4}{|l|}{$\mathrm{FDP}=$ fibrin degradation product } \\
\hline \multirow{2}{*}{\multicolumn{4}{|c|}{$\begin{array}{l}\mathrm{HCT}=\text { hematocrit } \\
\mathrm{HCY}=\text { homocysteine }\end{array}$}} \\
\hline & & & \\
\hline \multicolumn{4}{|l|}{ hsCRP $=$ high-sensitivity $\mathrm{C}$-reactive protein } \\
\hline \multicolumn{4}{|l|}{$\begin{array}{l}\text { BNP = brain natriuretic peptide } \\
\text { PL }=\text { physical limitation }\end{array}$} \\
\hline \multirow{2}{*}{\multicolumn{4}{|c|}{$\begin{array}{l}\mathrm{PL}=\text { physical limitation } \\
\mathrm{AS}=\text { angina stabilization }\end{array}$}} \\
\hline \multirow{2}{*}{$\begin{array}{l}\mathrm{AS}=\text { angina stabilization } \\
\mathrm{AF}=\text { angina frequency }\end{array}$} & & & \\
\hline & & & \\
\hline \multicolumn{4}{|l|}{$\mathrm{TS}=$ treatment satisfaction } \\
\hline $\mathrm{DP}=$ disease perception & & & \\
\hline
\end{tabular}

ical limitation $(P=.01)$, treatment satisfaction $(P=.004)$, and disease perception $(P=.007)$ scores compared with their normal-mild OSA counterparts (Table 3). Treatment satisfaction score decreased in association with AHI $(\mathrm{r}=0.48, P=.001)$ and ODI $(\mathrm{r}=0.49, P=.001)$ (Fig. 4 [bottom] and Table 4).
Inflammatory Markers and Quality of Life in Medical Management Subjects

The full analysis results of medical management subjects are presented in the supplemental materials (see supplementary Table S1 at http://www.rcjournal.com). Sub- 


\section{Effect of OSA on Percutaneous Coronary Intervention Subjects}

Table 4. Linear Regression Model for High-Sensitivity C-Reactive Protein and Treatment Satisfaction

\begin{tabular}{|c|c|c|c|c|c|c|c|c|}
\hline \multirow{2}{*}{ Factor } & \multicolumn{4}{|c|}{ High-Sensitivity C-Reactive Protein } & \multicolumn{4}{|c|}{ Treatment Satisfaction* } \\
\hline & Coefficients & $P$ & $\mathrm{CI} \dagger$ & $\mathrm{R}^{2}$ & Coefficients & $P$ & $\mathrm{CI} \dagger$ & $\mathrm{R}^{2}$ \\
\hline AHI & 0.101 & .047 & $0.001-0.201$ & 0.13 & -0.267 & .001 & -0.421 to -0.113 & 0.26 \\
\hline ODI & 0.111 & .03 & $0.012-0.211$ & 0.14 & -0.270 & .001 & -0.423 to 0.116 & 0.26 \\
\hline
\end{tabular}

* Adjusted for age and sex.

$\dagger 95 \%$ CI for coefficients.

$\mathrm{AHI}=$ apnea-hypopnea index

$\mathrm{ODI}=$ oxygen desaturation index
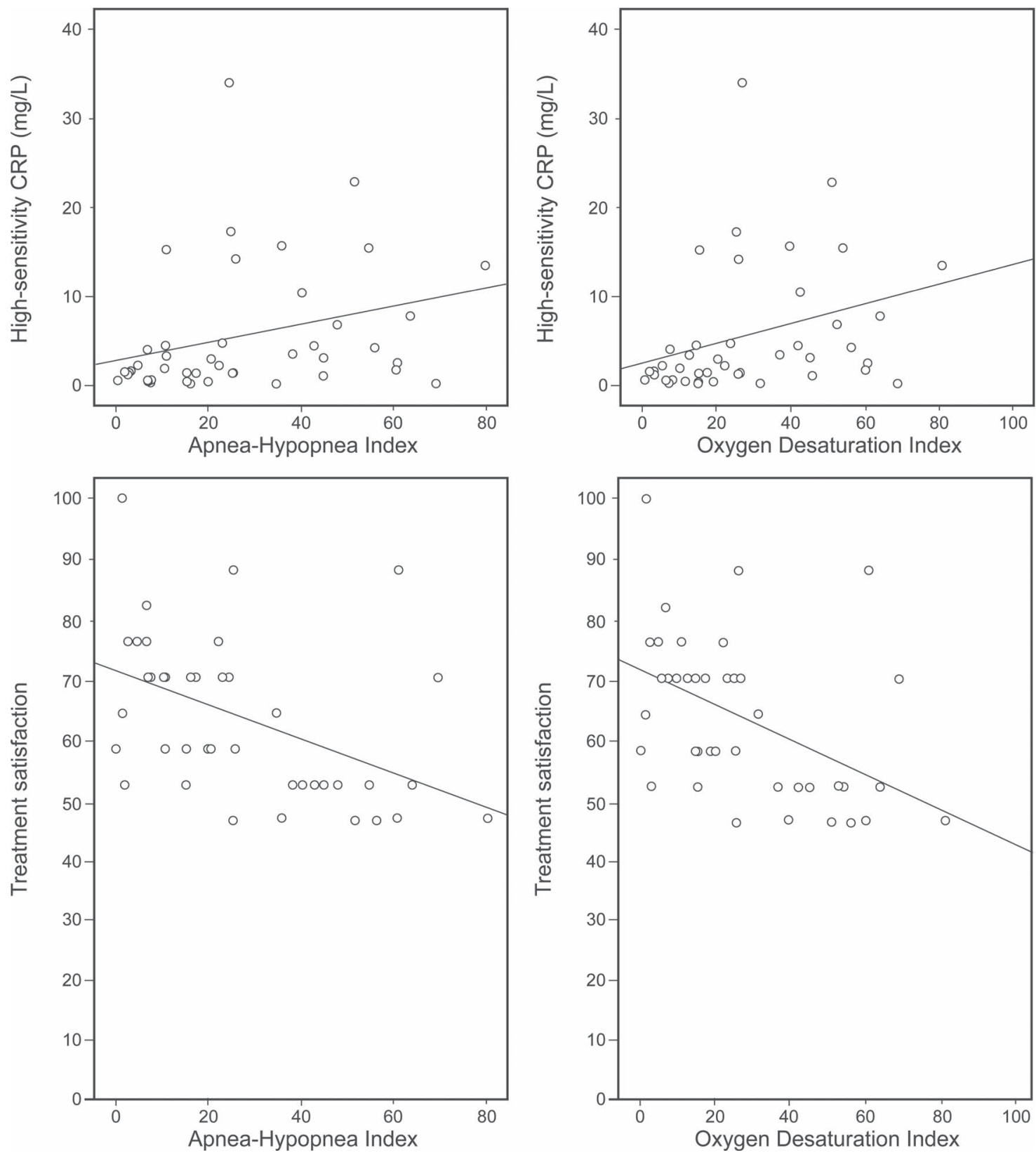

Fig. 4. Regression analysis showed that high-sensitivity C-reactive protein and treatment satisfaction were correlated with apnea-hypopnea index and oxygen desaturation index. CRP $=$ C-reactive protein. 


\section{Effect of OSA on Percutaneous Coronary Intervention Subjects}

jects with moderate-severe OSA showed worse treatment satisfaction $(P=.003)$ and anginal stability $(P=.02)$ scores compared with their normal-mild OSA counterparts.

\section{Discussion}

Adults with acute coronary syndrome undergoing percutaneous coronary intervention during their admission have a high prevalence of moderate to severe OSA. Those with moderate and severe OSA have elevated inflammatory markers, such as high-sensitivity C-reactive protein, homocysteine, and hematocrit, compared with those with up to mild OSA. Finally, OSA was associated with worse quality of life by the Seattle Angina Questionnaire. These findings have important clinical implications.

The pathophysiological mechanisms underlying the relationship between OSA and acute coronary syndrome are under active study. Most experts suggest multifactorial processes involving a wide range of mechanisms that may affect future risk of complications from coronary artery disease. Among them, inflammatory processes are critical in the pathogenesis of atherosclerosis. Previous studies indicated that intermittent hypoxia sustains inflammation through the activation of transcription of nuclear factor kappa B and hypoxia-inducible factor-1, which is activated by a high burden of intermittent hypoxia, and it increases systemic inflammation by modifying the levels of inflammation mediators (eg, tumor necrosis factor alpha and interleukin-8) and prolongs the natural life of myeloid cells. ${ }^{13}$ Moreover, through the reduction of serum oxygen levels, OSA increases inflammatory cell adhesion to the vascular endothelium, and at the same time it promotes the activation of pro-inflammatory cytokines and other inflammation markers involved in atherosclerosis. ${ }^{8} \mathrm{C}$-reactive protein, homocysteine, and B-type natriuretic peptide play a key role..$^{8,14,15}$

Our results support an inflammatory connection between OSA and coronary artery disease because high-sensitivity C-reactive protein and homocysteine were statistically elevated in those with severe OSA. Our results support the idea of a relationship between higher levels of inflammatory mediators and intermittent hypoxia and reoxygenation caused by OSA. Although it lacks specificity, increased C-reactive protein level is one of the most significant predictors of cardiovascular risk and prognosis. ${ }^{16}$ High levels of high-sensitivity C-reactive protein have a close relation with cardiovascular disease mortality in OSA patients. Previously, it has been shown that C-reactive protein has pro-atherogenic proprieties itself. ${ }^{8}$

In addition, C-reactive protein increases plasminogen activator inhibitor-1 (PAI-1) levels. ${ }^{17}$ PAI-1 inhibits the enzyme tissue plasminogen activator (important for blood clot dissolution); thus, it plays an important role in the regulation of fibrinolytic activity. ${ }^{18} \mathrm{~A}$ systemic inflamma- tory state may activate clotting pathways, leading to atherosclerotic plaque instability and rupture resulting in acute coronary syndrome. In summary, high C-reactive protein levels have been a risk factor highly associated with increased cardiovascular mortality in OSA subjects.

Another inflammatory mediator, homocysteine, contains a sulfur-containing amino acid, which is considered a cardiovascular risk biomarker ${ }^{19}$ and has been related to the risk of developing myocardial infarction, hypertension, and atherosclerosis. ${ }^{20}$ Levels of homocysteine are mediated by endothelial injury, altered coagulation, and platelet activation. Our data show higher homocysteine levels in subjects with more severe OSA. Also, these previous studies' results suggest that homocysteine might be considered an important mediator of endothelial damage in OSA ${ }^{21-23}$; this may mark high risk for future coronary events and indicate a poor prognosis of acute coronary syndrome.

Previous studies show that individuals with hypoxic conditions often have increased hematocrit. ${ }^{24}$ Several studies have determined that the increased hematocrit correlates positively with OSA severity. ${ }^{25}$ Consistent with our results, a previous study 26 indicated that there was a statistically significant increase in hematocrit levels, which means that, combined with moderate to severe OSA, subjects would have more viscous blood and be more likely to form clots.

Our team previously identified 390 subjects with OSA who had undergone a percutaneous coronary intervention between 2002 and 2012 and provided unique evidence that untreated moderate-severe OSA was an independent risk factor for repeat revascularization after percutaneous coronary intervention and that CPAP therapy can reduce this risk. ${ }^{3}$ However, Jullian-Desayes et $\mathrm{al}^{27}$ provided a systematic analysis of randomized studies that compared therapeutic versus sham CPAP intervention or CPAP withdrawal. Their results showed that CPAP therapy should not be expected to cause a clinically relevant decrease in cardiometabolic biomarkers in unselected OSA patients. Future studies will show whether the cardiovascular warning signal biomarker levels will decrease among percutaneous coronary intervention subjects with OSA treatment with CPAP therapy after percutaneous coronary intervention.

Our data also show statistically significant differences in treatment satisfaction and disease perception by the Seattle Angina Questionnaire by OSA status. With the severity of OSA increasing, the scores for physical limitation, treatment satisfaction, and disease perception decreased. However, the other 2 dimensions, including angina stabilization and angina frequency, showed no statistically significant difference among OSA groups. Gagnon et $\mathrm{al}^{28}$ suggested that OSA is a risk factor for developing mild cognitive impairment, such as sensitivity, depression, and anxiety tendency, that can be observed by patients' 


\section{Effect of OSA on Percutaneous Coronary Intervention Subjects}

families. However, a systemic review ${ }^{29}$ containing 12 studies on OSA and cognitive impairment reported that cognitive complaints were at least partially related to subjective sleepiness, and OSA was not necessarily a sign of objective cognitive impairment. This area needs more work but could explain our quality of life findings.

Geovanini et al ${ }^{30}$ reported a cross-sectional study comparing stable angina subjects $(n=70)$ and refractory angina pectoris subjects $(n=70)$. The results showed that subjects with refractory angina pectoris had a higher AHI level, Epworth Sleepiness Scale score, and depression score (Beck questionnaire). They stressed that OSA and depression were independently associated with refractory angina and may contribute to poor cardiovascular outcome. Lespérance et $\mathrm{al}^{31}$ indicated that depression could increase 4-fold the risk of non-fatal myocardial infarction and sudden cardiac death in patients with stable angina. Other studies $^{4,32}$ also agreed that OSA and depression were independent risk factors of poor cardiovascular prognosis. Iles-Smith et $\mathrm{al}^{33}$ indicated that anxiety was a predictor of readmission following percutaneous coronary intervention postoperatively. In our research, the treatment satisfaction score decreases in association with AHI and ODI, thus suggesting that hypoxia induced by OSA could decrease an individual's treatment satisfaction. A depressive state directly influences treatment satisfaction, so we have reason to speculate that the change in subjects' treatment satisfaction is due to the existence of depression related to worse symptoms. It is worth noting that there are common pathways of depression and OSA effects on human physiology, including abnormal autonomic nervous system, inflammation, endothelial dysfunction, and blood coagulation abnormality. ${ }^{34}$ These factors may be the reason why OSA affects the treatment satisfaction score.

There are several limitations to our study. Our sample size is relatively small, which may lead to reduced power and bias. On account of the observational nature of our research, we cannot completely eliminate the possibility of residual confounding. Nonetheless, this effort is the first to investigate the severity of OSA in subjects who undergo percutaneous coronary intervention and to characterize potential effects on subjects' subjective cognition, parameters important to percutaneous coronary intervention and acute coronary syndrome outcomes. Future prospective and large-scale studies can surmount these barriers and provide important information on this topic.

\section{Conclusions}

Adults with acute coronary syndrome undergoing percutaneous coronary intervention have a high prevalence of moderate to severe OSA. Percutaneous coronary intervention subjects have a higher ODI, a higher level of inflammatory mediators, and a lower treatment satisfaction and disease perception, which may increase the risk of adverse events. Randomized, double-blind controlled trials are needed to determine whether OSA treatment can decrease the systemic inflammatory response, improve the patients' disease perception and treatment satisfaction, and reduce the occurrence of cardiovascular sequelae.

\section{ACKNOWLEDGMENTS}

We thank all of the staff for help in extracting data from the Beijing An Zhen Hospital Sleep Center. We also thank the staff from the Beijing An Zhen Hospital Cardiovascular Department for assistance with subjects. Dr JM Pinto (University of Chicago) provided helpful advice and editorial input.

\section{REFERENCES}

1. Kasai T, Floras JS, Bradley TD. Sleep apnea and cardiovascular disease: a bidirectional relationship. Circulation 2012;126(12):14951510 .

2. Nakashima H, Kurobe M, Minami K, Furudono S, Uchida Y, Amenomori K, et al. Effects of moderate-to-severe obstructive sleep apnea on the clinical manifestations of plaque vulnerability and the progression of coronary atherosclerosis in patients with acute coronary syndrome. Eur Heart J Acute Cardiovasc Care 2015;4(1):75-84.

3. Wu X, Lv S, Yu X, Yao L, Mokhlesi B, Wei Y. Treatment of OSA reduces the risk of repeat revascularization after percutaneous coronary intervention. Chest 2015;147(3):708-718.

4. Marin JM, Carrizo SJ, Vicente E, Agusti AG. Long-term cardiovascular outcomes in men with obstructive sleep apnoea-hypopnoea with or without treatment with continuous positive airway pressure: an observational study. Lancet 2005;365(9464):1046-1053.

5. Cassar A, Morgenthaler TI, Lennon RJ, Rihal CS, Lerman A. Treatment of obstructive sleep apnea is associated with decreased cardiac death after percutaneous coronary intervention. J Am Coll Cardiol 2007;50(14):1310-1314.

6. Yumino D, Wang H, Floras JS, Newton GE, Mak S, Ruttanaumpawan $\mathrm{P}$, et al. Prevalence and physiological predictors of sleep apnea in patients with heart failure and systolic dysfunction. J Card Fail 2009;15(4):279-285.

7. Polonski L, Gasior M, Gierlotka M, Osadnik T, Kalarus Z, TruszGluza M, et al. A comparison of ST elevation versus non-ST elevation myocardial infarction outcomes in a large registry database: are non-ST myocardial infarctions associated with worse long-term prognoses? Int J Cardiol 2011;152(1):70-77.

8. Vitulano N, Di Marco Berardino A, Re A, Riccioni G, Perna F, Mormile F, et al. Obstructive sleep apnea and heart disease: the biomarkers point of view. Front Biosci 2013;5:588-599.

9. Thornton AT, Singh P, Ruehland WR, Rochford PD. AASM criteria for scoring respiratory events: interaction between apnea sensor and hypopnea definition. Sleep 2012;35(3):425-432.

10. Spertus JA, Winder JA, Dewhurst TA, Deyo RA, Fihn SD. Monitoring the quality of life in patients with coronary artery disease. Am J Cardiol 1994;74(12):1240-1244.

11. Liu S. Reliability, validity and reaction degree of Seattle Angina Questionnaire (SAQ) Chinese version. Tianjin Medical University Degree Thesis 2003;53.

12. Johns MW. A new method for measuring daytime sleepiness: the Epworth sleepiness scale. Sleep 1991;14(6):540-545.

13. Taylor CT. Interdependent roles for hypoxia inducible factor and nuclear factor- $\kappa \mathrm{B}$ in hypoxic inflammation. J Physiol 2008;586(17): 4055-4059. 


\section{Effect of OSA on Percutaneous Coronary Intervention Subjects}

14. Sun Q, Jia X, Gao J, Mou W, Tong H, Wen X, Tian Y. Association of serum homocysteine levels with the severity and calcification of coronary atherosclerotic plaques detected by coronary CT angiography. Int Angiol 2014;33(4):316-323.

15. Katsanos S, Babalis D, Kafkas N, Mavrogenis A, Leong D, Parissis $\mathrm{J}$, et al. B-type natriuretic peptide vs. cardiac risk scores for prediction of outcome following major orthopedic surgery. J Cardiovasc Med 2015;16(6):465-471.

16. Koenig W. Predicting risk and treatment benefit in atherosclerosis: the role of C-reactive protein. Int J Cardiol 2005;98(2):199-206.

17. Ji Y, Fish PM, Strawn TL, Lohman AW, Wu J, Szalai AJ, Fay WP. $\mathrm{C}$-reactive protein induces expression of tissue factor and plasminogen activator inhibitor-1 and promotes fibrin accumulation in vein grafts. J Thromb Haemost 2014;12(10):1667-1677.

18. Zamarrón C, Ricoy J, Riveiro A, Gude F. Plasminogen activator inhibitor-1 in obstructive sleep apnea patients with and without hypertension. Lung 2008;186(3):151-156.

19. Wang H, Liu J, Wang Q, Zhao H, Shi H, Yu X, et al. Descriptive study of possible link between cardioankle vascular index and homocysteine in vascular-related diseases. BMJ Open 2013;3(3): e002483. doi: 10.1136/bmjopen-2012-002483.

20. Ozkan Y, Firat H, Simşek B, Torun M, Yardim-Akaydin S. Circulating nitric oxide (NO), asymmetric dimethylarginine (ADMA), homocysteine, and oxidative status in obstructive sleep apnea-hypopnea syndrome (OSAHS). Sleep Breath 2008;12(2):149-154.

21. Cintra F, Tufik S, D'Almeida V, Calegare BF, de Paola A, Oliveira W, et al. Cysteine: a potential biomarker for obstructive sleep apnea. Chest 2011;139(2):246-252.

22. Niu X, Chen X, Xiao Y, Dong J, Zhang R, Lu M, Kong W. The differences in homocysteine level between obstructive sleep apnea patients and controls: a meta-analysis. PLoS One 2014;9(4):e95794. doi: 10.1371/journal.pone.0095794.

23. Sariman N, Levent E, Aksungar FB, Soylu AC, Bektaş O. Homocysteine levels and echocardiographic findings in obstructive sleep apnea syndrome. Respiration 2010;79(1):38-45.
24. Yelmen N, Ozdemir S, Guner I, Toplan S, Sahin G, Yaman OM, Sipahi S. The effects of chronic long-term intermittent hypobaric hypoxia on blood rheology parameters. Gen Physiol Biophys 2011; 30(4):389-395.

25. Choi JB, Loredo JS, Norman D, Mills PJ, Ancoli-Israel S, Ziegler MG, Dimsdale JE. Does obstructive sleep apnea increase hematocrit? Sleep Breath 2006;10(3):155-160.

26. Liak C, Fitzpatrick M. Coagulability in obstructive sleep apnea. Can Respir J 2011;18(6):338-348.

27. Jullian-Desayes I, Joyeux-Faure M, Tamisier R, Launois S, Borel AL, Levy P, Pepin JL. Impact of obstructive sleep apnea treatment by continuous positive airway pressure on cardiometabolic biomarkers: a systematic review from sham CPAP randomized controlled trials. Sleep Med Rev 2015;21:23-38.

28. Gagnon K, Baril AA, Gagnon JF, Fortin M, Décary A, Lafond C, et al. Cognitive impairment in obstructive sleep apnea. Pathol Biol 2014;62(5):233-240.

29. Vaessen TJ, Overeem S, Sitskoorn MM. Cognitive complaints in obstructive sleep apnea. Sleep Med Rev 2015;19:51-58.

30. Geovanini GR, Gowdak LH, Pereira AC, Danzi-Soares Nde J, Dourado LO, Poppi NT, et al. OSA and depression are common and independently associated with refractory angina in patients with coronary artery disease. Chest 2014;146(1):73-80.

31. Lespérance F, Frasure-Smith N, Juneau M, Théroux P. Depression and 1-year prognosis in unstable angina. Arch Intern Med 2000; 160(9):1354-1360.

32. Herrmann C, Brand-Driehorst S, Buss U, Rüger U. Effects of anxiety and depression on 5-year mortality in 5,057 patients referred for exercise testing. J Psychosom Res 2000;48(4):455-462.

33. Iles-Smith H, McGowan L, Campbell M, Mercer C, Deaton C. A prospective cohort study investigating readmission, symptom attribution and psychological health within six months of primary percutaneous coronary intervention. Eur J Cardiovasc Nurs 2015;14(6): 506-515.

34. Celano CM, Huffman JC. Depression and cardiac disease: a review. Cardiol Rev 2011;19(3):130-142. 